\title{
RIBEIRO, Gustavo Lins. 2014. Outras globalizações: cosmopolíticas pós-imperialistas
}

Rio de Janeiro: EDUERJ. 314 pp.

João Paulo Aprígio Moreira

\section{(2) OpenEdition}

\section{Journals}

\section{Edição electrónica}

URL: http://journals.openedition.org/aa/1482

DOI: $10.4000 /$ aa. 1482

ISSN: 2357-738X

\section{Editora}

Programa de Pós-Graduação em Antropologia Social (UnB)

Edição impressa

Data de publição: 1 dezembro 2015

Paginação: 271-275

ISSN: 0102-4302

Refêrencia eletrónica

João Paulo Aprígio Moreira, «RIBEIRO, Gustavo Lins. 2014. Outras globalizações: cosmopolíticas pósimperialistas», Anuário Antropológico [Online], v.40 n.2 | 2015, posto online no dia 01 junho 2018, consultado o 28 abril 2021. URL: http://journals.openedition.org/aa/1482 ; DOI: https://doi.org/ 10.4000/aa.1482

Este documento foi criado de forma automática no dia 28 abril 2021.

\section{(c) (i) $(9)$}

Anuário Antropológico is licensed under a Creative Commons Atribuição-Uso Não-Comercial-Proibição de realização de Obras Derivadas 4.0 International. 


\title{
RIBEIRO, Gustavo Lins. 2014. Outras globalizações: cosmopolíticas pós- imperialistas
}

Rio de Janeiro: EDUERJ. 314 pp.

\author{
João Paulo Aprígio Moreira
}

\section{REFERÊNCIA}

RIBEIRO, Gustavo Lins. 2014. Outras globalizações: cosmopolíticas pós-imperialistas. Rio de Janeiro: EDUERJ. 314 pp.

1 Temas como a globalização (em seus aspectos políticos, econômicos e culturais), as relações entre antropologia e sistemas de poder, o "desenvolvimento", a diversidade cultural, o multiculturalismo, os direitos humanos, o ciberespaço, as cópias e o(s) colonialismo(s) são contemporâneos e raramente atravessam a trajetória de um pesquisador de forma tão propositiva como na de Gustavo Lins Ribeiro. Em seu livro Outras globalizações: cosmopolíticas pós-imperialistas, é possível vislumbrar abordagens sobre esses temas. Sua leitura possibilita a construção de novos objetos de pesquisa, o que é sabido, mérito de bons trabalhos.

O livro problematiza a universalização de discursos, que o autor designa como cosmopolíticas, bem como descreve as aporias que marcam tais processos inseridos em diversas redes de poder. A obra resulta de mais de uma década de pesquisas realizadas na Universidade de Brasília, onde o autor é professor titular (e recentemente aposentado), e nas amplas redes que mobiliza. Está dividido em três partes e cada uma possui três capítulos. Alguns dos artigos frutos das interlocuções do autor receberam sua primeira tradução para o português nesse volume. Outro aspecto importante é a facilidade de encontrar, reunidos no livro, artigos do autor distribuídos em importantes periódicos internacionais e nacionais. É o caso do capítulo "Poder, redes e ideologias no campo do desenvolvimento", que tem inspirado diversos pesquisadores que se 
debruçam sobre o tema. É possível perceber o livro, portanto, como mais que um resultado de pertinentes reflexões acerca de problemas do mundo contemporâneo; é também um corolário de esforços políticos e práticos do autor perante desafios colocados por novas formas de hegemonias, criando uma sintonia rara entre projetos $\mathrm{e}$ resultados, o que já de início traz grande valor à obra.

3 Com base em uma perspectiva interdisciplinar utilizada de forma cuidadosa para que conceitos e ideias não fiquem "fora do lugar" - parafraseando a citação de Roberto Schwarz -, Lins Ribeiro explora os cruzamentos entre uma sociologia crítica, a economia política, a história e a etnografia, propondo uma reflexão sobre a antropologia como uma cosmopolítica. Para tanto, utiliza como quadro de referência a produção dos discursos antropológicos e do pensamento social latino-americano e sua importância para um contexto de políticas transnacionais, sobretudo no que diz respeito ao trabalho acadêmico e às assimetrias de poder presentes nessas relações e na tensão decorrente da circulação desses discursos em âmbito local ou global.

Considerando uma proposta heterodoxa para a antropologia, cada vez mais rara em tempos como o que descreve como "crise das representações" e "fim das utopias" e que impactam não só a nossa disciplina, mas o cenário geopolítico global, o autor nos contempla com uma escrita que privilegia a heteroglossia, sem se descurar do papel político das políticas da diferença na contemporaneidade. Para Lins Ribeiro, essas políticas surgiriam de demandas étnicas e culturais por reconhecimento, às vezes, esvaziadas em discursos que pululam dentro da própria antropologia ao problematizarem conceitos como identidade, cultura e etnicidade.

Dessa maneira, na primeira parte do livro, o autor sugere uma ideia de globalização no plural, após a apresentação do conceito e sua multiplicidade de sentidos na economia política. Caracteriza diversos tipos de globalizações e seus impactos em diferentes espaços. Sua tese da substituição do tema do "desenvolvimento" pelo da globalização na agenda das principais agências multilaterais sugere a emergência de movimentos contra-hegemônicos. Isso está fundamentado em pesquisa empírica de dois objetos inseridos no que Lins Ribeiro designa como "globalização política não hegemônica": os movimentos de rua do tipo Occupy (retorno de uma perspectiva anarquista e descentralizada, que o autor, com base em uma genealogia, relaciona com aspectos do Movimento Zapatista), bem como os Fóruns Sociais Mundiais. Lins Ribeiro propõe dois conceitos analíticos poderosos para entender esses dois objetos. $O$ primeiro seria caracterizado como um movimento antiglobalização, e o segundo, como um movimento alterglobalização. Após demarcar as diferenças entre ambos, o autor aponta para o que eles têm em comum: o rechaço às políticas neoliberais que estão presentes nas ideias de globalização e que tomaram o mundo a partir da queda do Muro de Berlim. Lins Ribeiro se dedica ainda ao que chama de "globalização popular", propondo uma análise da circulação de bens e pessoas em "mercados informais" e problematizando tal categorização desses espaços, bem como categorias como "lícito" e "ilícito", "legal" e "ilegal".

6 No que diz respeito ao terceiro aspecto da globalização - que encerra essa primeira parte, intitulada "Outras globalizações políticas, econômicas e acadêmicas" -, é a geopolítica do conhecimento que interessa a Lins Ribeiro, tomando emprestada a noção do latino-americanista Walter Mignolo. $O$ autor chama atenção para a necessidade de entender as agências multilaterais e os atores translocais em um contexto de cultura global. As implicações de tal perspectiva na política acadêmica reverberaram na prática 
do autor e tiveram como um dos resultados esse capítulo do livro, que relata os desafios de uma proposta de antropologias mundiais e a fundação da WCAA (The World Council of Anthropological Associations). Para o autor, é imperioso um processo de descolonização do conhecimento, que passa pela abertura de espaços institucionais como esse, em um contexto de globalização acadêmica que cria assimetrias de poder, diante da crise dos sujeitos. Lins Ribeiro destaca, ainda, aspectos como a reinvenção, a polifonia e as desigualdades nas trocas, sobretudo, com base na questão linguística e na retroalimentação de teorias que têm os Estados Unidos como um dos principais centros hegemônicos da produção intelectual.

7 Na segunda parte do livro, intitulada "Pós-imperialismos e cosmopolíticas", o autor se dedica a outras cosmopolíticas que não a da antropologia. A noção de cosmopolítica inicia a seção, sendo caracterizada como discursos políticos conscientes que se pretendem universais e que, ao evidenciarem seus locais de fala, historicamente e socialmente contextualizados, passariam a levar vantagem em discursos universalistas que buscam ser hegemônicos. A tensão entre o universal e o particular é o tema do capítulo posterior, que reflete sobre a circulação desses discursos. Em seguida, ao propor a noção de pós-imperialismo, Lins Ribeiro posiciona a América Latina nos debates sobre o pós-colonialismo, mostrando como o termo é anacrônico quando se tem o processo de descolonização latino-americana como horizonte específico de análise em relação aos processos que ensejaram as reflexões das teorias pós-coloniais no espaço acadêmico anglo-americano. Transladadas para o contexto latino-americano com fortes marcas mexicanas e andinas, tais reflexões encobririam a especificidade de diversas outras experiências que constituem os processos de independência e construção dos Estados-nações na América Latina.

O tema do capítulo seguinte é a cosmopolítica dos discursos sobre o "desenvolvimento", tema tratado por Lins Ribeiro à luz da noção de "campo" de Pierre Bourdieu. Por fim, para encerrar essa parte em último capítulo, o autor nos apresenta a relação entre conceitos como o de particularismos locais e particularismos cosmopolitas, acompanhando-os em suas transformações em discursos globais, como o da diversidade cultural. Sem abrir mão do complexo debate que tal conceito suscita nas teorias antropológicas e da assunção do termo na economia simbólica global, ao lado de outras cosmopolíticas, como a dos direitos humanos, o autor analisa comparativamente as declarações da ONU, no sentido de problematizar seus limites, tendo como horizonte a governança global. Lins Ribeiro aponta, assim, a tensão entre a globalização, a diversidade e os limites da pretensão de discursos globais como o dos direitos humanos e do desenvolvimento, bases da política contemporânea.

9 Em "Espaços e debates transnacionais e globais", terceira e última parte do livro, Lins Ribeiro se dedica a temas específicos relacionados aos temas mais gerais discutidos nos capítulos anteriores, ainda na chave de sua proposta de entendimento das formas atuais de reprodução de hegemonias. Primeiramente, faz uma reflexão sobre o espaço público virtual. Para tanto, propõe o conceito de comunidades imaginadas virtuais, em diálogo direto com o de "comunidades imaginadas" de Benedict Anderson. Lins Ribeiro chama atenção para o caráter virtual que constitui qualquer comunidade, já que tem como bases signos e sistemas simbólicos como matriz da qual deriva sua virtualidade. Para além das discussões contemporâneas que associam esse tipo de relação apenas à base da cultura tecnocientífica e que têm o ciberespaço como lócus de (re)produção, o autor ressalta que a internet produz impactos específicos passíveis de ser etnografados. 
Cita, como exemplo, o crescente testemunho dos ativismos políticos surgidos nesse contexto - caso analisado, em detalhe, na primeira parte do livro, quando o autor se detém na atuação de movimentos sociais, que ele denominou como movimentos antiglobalização e que têm a internet como um de seus principais veículos de mobilização.

Lins Ribeiro aponta também os dilemas da construção de um espaço público virtual, onde destaca, primeiramente, seu caráter contestatório - vide os usos da internet para além do controle dos Estados-nações e do capitalismo global -, bem como seu oposto: a normatização dos fluxos de informação que estariam sob o monopólio dos mesmos. Todavia, segundo o autor, o ciberespaço público representa um desafio à noção de espaço público real, já que é um espaço desterritorializado onde novas questões de extraterritorialidade se impõem, o que chamou de "criptoanarquia". Chama ainda atenção para questões como a capacidade de vigilância dos Estados sobre seus cidadãos no ambiente virtual, bem como a cobrança de impostos sobre negócios realizados na internet. Ao problematizar as relações entre o real, o virtual e o imaginário, Ribeiro propõe que essas relações devem ser entendidas muito mais como uma relação de trânsito do que como uma oposição entre esferas. Para o virtual, o autor salienta uma especificidade: as possibilidades de entrar e sair (modo on-line e off-line) não disponíveis aos outros termos da relação.

11 Em “O que há em uma cópia?", as reflexões do autor estão atreladas às questões suscitadas ainda na primeira parte do livro, quando tematiza o que chamou de "globalização popular", referente à globalização econômica - os mercados de produtos piratas que constituem o que o autor denomina como um sistema mundial não hegemônico. Por fim, como último capítulo, sob a luz das discussões sobre cosmopolíticas e pós-imperialismo, Lins Ribeiro descreve a construção de Brasília como uma experiência pós-imperialista específica na América Latina, buscando dar suporte a sua crítica às limitações de discursos pós-coloniais para o caso latino-americano.

o livro traz perspectivas instigantes para tensões que envolvem discursos contemporâneos de contestação às hegemonias - no que diz respeito tanto a meios (movimentos sociais, espaço virtual, megarrituais) como a fins (ideologias, utopias e cosmopolíticas) que embasam tais práticas, proporcionando uma profícua relação entre questões antropológicas contemporâneas e poder. Nesse sentido, a obra tem o mérito de fomentar o desejo de troca como um parti pris do mundo contemporâneo, sem negligenciar, contudo, o fato de essas trocas ocorrerem em espaços de produção desigual de poder.

\section{AUTORES}

JOÃO PAULO APRÍGIO MOREIRA

UEMS 